help book, there is no place in it for Andrews' concerns about the medical model, such as inappropriate pressure by health-care professionals on patients to undergo genetic testing. Nevertheless, the style in which Milunsky's book is written does raise other concerns raised by Andrews, such as the dangers of overstating the benefits of knowing one's genetic predispositions and susceptibilities. Is it really reasonable to expect that, by following Milunsky's advice, informative though it is, you will save your life?

Both books are very readable and are based on wide knowledge of the literature. Milunsky has user-friendly charts and diagrams; Andrews' book is written in a conversational style. Although Andrews offers a conceptual framework for assessing claims about genetics, her work is set in the same socio-cultural context as Milunsky's. Other conceptual frameworks are therefore possible which might be less individualistic than the fundamental-rights model. By adopting a more socially based position, where individuals have responsibilities as well as rights, it might be possible to find a position between the public-health and individualrights models. There may be moral reasons, arising out of a sense of social solidarity, for example, why individuals should agree to participate in screening programmes and population-genetic research, provided that adequate protections are in place.

Ruth Chadwick is at the Institute for Environment, Philosophy and Public Policy, Lancaster University, Lancaster LA1 4YG, UK.

\section{Physics for non-physicists}

Hidden Unity in Nature's Laws

by John C. Taylor

Cambridge University Press: 2001. 490 pp.

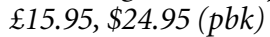

\section{Peter Landsberg}

Are you lost in modern theoretical physics? Do you need help with understanding squarks, selectrons, photinos? Or do you require guidance on the subject of the Higgs particle? Perhaps you need a hint as to the meaning of quintessence in cosmology? If any of these apply, then this is the book for you. But it is rather voluminous, and with good reason. It not only deals with modern ideas, but also with well-established, older theories such as newtonian gravitation, the origin of quantum theory and relativity. It is down-to-earth, however, so there is nothing on the origin of life, tired light or quantum computing.

The distinguished author describes his book as offering "a non-technical tour through the principles of physics". This is a

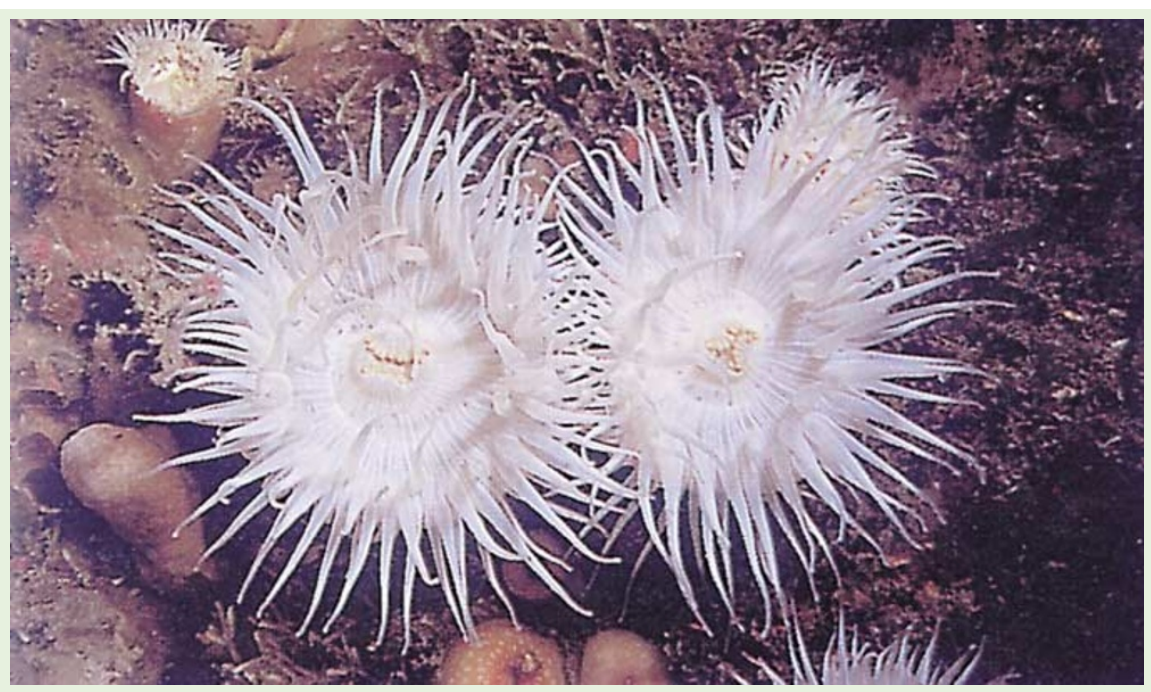

\title{
Wonders of the shallows
}

The anemone Sagartia elegans, above, is found on rocky shores and in rock pools along the Atlantic, North Sea and Channel coasts of northern Europe down to the Mediterranean. It is just one of the diverse species featured in Photographic Guide to the Sea \& Shore Life of

good description, but one might add two provisos. First, he delves to some extent into string theory, discusses quantum gravity, penetrates to Grassmann variables, and so on. Although these topics are well explained, it would clearly be misleading to call them 'nontechnical'. Second, experimental questions of physics are largely omitted, so a better description of the book would be 'a semi-technical survey of current theoretical physics'.

Regarded in this light, the book is an undoubted success. John Taylor does not try to exaggerate results or make unsupported claims, and he attempts at all times to elucidate complicated matters in simple language. When one deals with superspace, quaternions and the like, this is of course almost

\section{For reference}

\section{The Penguin Desk Encyclopedia of Science and Mathematics by Bryan Bunch \& Jenny Tesar \\ Viking Penguin, $\$ 40$}

\section{The Oxford Companion to the Earth} edited by Paul L. Hancock

Oxford University Press, $\mathfrak{£ 3 9 . 5 0}$

\section{A Dictionary of the History of Science}

by Anton Sebastian

Parthenon, £38, \$65

\section{Encyclopedia of Genetics}

edited by Eric C. R. Reeve

Fitzroy Dearborn, $£ 105$
Britain \& North-west Europe by Ray Gibson, Benedict Hextall and Alex Rogers (Oxford

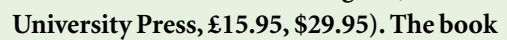
marks the start of a new series of photographic guides to aid the identification and promote the conservation of Europe's plants and creatures.

impossible, but Taylor at least has a go.

He also gives some interesting, although not novel, historical insights, including Arthur Eddington's expedition to check on the deflection of light by the Sun and a summary of what various contemporaries thought of Niels Bohr. In addition, Chapter 1 gives a good account of the development of gravitation theory leading to Newton's work.

There are some remarks about the theory of black holes as well as cosmology, and the singularities that occur in these contexts. I expected Taylor to assert at this stage that singularities are normally unphysical, and so cannot exist in nature. However he does not quite take this rather radical step. In the same vein, he observes that "people have often wondered whether the idea of a true point (for particles or charges) was realistic" and so, justifying an extra dimension, he introduces strings to his readers. But a reader may well think that a one-dimensional object is still too idealized. Taylor anticipates this, for he points out that using higher dimensions would lead to rather intractable mathematics.

$\mathrm{He}$ also speaks repeatedly of "the universe", when he considers results of calculations. These calculations apply to models and not necessarily to the real Universe, so it would be better to refer to a 'model universe' in such cases. My final quibble refers to the assertion that "entropy should never decrease". But it does, of course, for all the materials in a refrigerator!

I know from personal experience that an author likes to see their book read by all qualified people, and indeed many people will be 
qualified to read this book. One reason is that the equations used are rather simple. But even simple equations are a barrier for those who have not done much mathematics, and this imposes an unfortunate restriction on the readership. This is a pity, for many worthwhile ideas are expounded here which even a newcomer to physics could understand. I strongly recommend this book.

Peter Landsberg is emeritus professor in the Faculty of Mathematical Studies, University of Southampton, Southampton SO17 1BJ, UK. His most recent book is Seeking Ultimates (Institute of Physics Publishing, 1999).

\section{The genetic complexity of life}

\section{The Misunderstood Gene}

by Michel Morange (translated by

Matthew Cobb)

Harvard University Press: 2001. 212 pp.

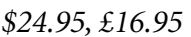

\section{Brian Charlesworth}

According to the preface of this book, which is a translation of a work in French originally entitled La Part des Gènes (Odile Jacob, 1998), Morange's aim is "to put forward a new vision of genes and their function based on recent results from molecular biology". He goes on to assert that "the concept of the gene that is used both by the general public and by many scientists is completely outmoded". By this, he is referring to the role of genes in determining protein structure.

His statement will come as a surprise to most geneticists, as this concept of primary gene function has long since become a truism. Morange seems to feel, however, that the nature and functions of genes are widely misunderstood (he is excluding professional geneticists, presumably), and that this misunderstanding contributes to a widespread hostility to genetic determinism. At one point, he even refers to "the opponents of molecular biology and genetics". These opponents are vaguely defined as people who attribute the complexity of life to components of organisms other than genes, and their views are not discussed in any detail. I felt, therefore, as though I was listening to only one side of an argument; and it is not very clear with whom the argument is being conducted, and why it started.

Most of what Morange has to say is, however, sensible and instructive, and he does an excellent job of presenting molecular, cellular and developmental aspects of genetics to readers who are not geneticists, but who have a fairly good knowledge of biology. Morange's main point is that the product of a single gene is only one part of a complex web of interacting proteins that results in the structure, functioning and behaviour of an organism. This is, in fact, an old idea, clearly stated in the writings of developmental geneticists such as C. H. Waddington and Sewall Wright in the 1940s and 1950s. The difference now is that molecular genetics has provided detailed evidence about the nature of some of the key players in the game and exactly how they interact with one another. Oddly enough, Morange devotes only a couple of pages to the way in which early embryonic development is controlled by genes, despite the breathtaking advances that have occurred in this field over the past 20 years.

Morange develops various important implications of the broader view of gene action, which he illustrates with concrete examples, mostly from human and mouse genetics. The first is that a change in the structure of a gene, as a result of a mutation or (nowadays) a 'knockout' experiment, may or may not have a drastic effect on the organism, depending on the place of the gene's product in the web of interacting gene products and the ability of the web to compensate for such a change.

Other implications are that multiple, and often surprising, complexes of changes in the organism's characteristics may arise from a single mutation; the nature or even the occurrence of changes may also depend on the nature of the environment, or on the state of other genes. When there is variation in a trait among people, as in their susceptibility to a given disease, a given gene may contribute only a minor part of the variation, and non-genetic factors frequently also con-

tribute to the variability. This applies especially to complex traits, such as behavioural characteristics and lifespan. Again, this all forms part of the stock-in-trade of classical developmental and quantitative genetics.

So genes do not have a one-to-one relation to the characters they affect, and any crude version of genetic determinism fails. This does not undermine the fundamental role of genes in encoding the sequences of amino acids in the polypeptide chains to which they correspond, and which, in turn, determine the three-dimensional structure and biochemical specificities of the folded proteins. Because only the genes are transmissible across generations, only they are subject to the forces of evolution. In a very real sense, therefore, Morange concludes, genes are the ultimate determinants of the development and evolution of organisms.

Little of this is new or controversial, but is probably worth presenting in some detail to show the general reader exactly what is meant by the genetic control of development and behaviour. The book concludes with a discussion of human evolution and eugenics. Morange is rightly cautious about the prospects for widespread genetic manipulation of human genetic material, although positive about limited interventions such as somatic gene therapy and selective abortion of individuals at high risk of genetic disease. Overall, the book is well written and accurate.

Brian Charlesworth is at the Institute for Cell, Animal and Population Biology, University of Edinburgh, Edinburgh EH9 3JT, UK.

\section{New in paperback}

Mystery of Mysteries: Is Evolution a Social Construction?

by Michael Ruse

Harvard University Press, \$19.95, £13.95

\section{Primeval Soup}

by Christopher Wills \& Jeffrey Bada

Perseus, $\$ 17$

"The authors provide an excellent and compelling written overview... this book provides a highly readable survey of the historical prelude to the study of the origins of life." William J. Hagan Nature 407, 451-452 (2000)

The Settlement of the Americas: A New Prehistory

by Thomas Dillehay

Basic Books, $\$ 18$

\section{Cradle of Life: The Discovery of} Earth's Earliest Fossils

by J. William Schopf

Princeton University Press, \$17.95, £11.95
The Natural Philosophy of James Clerk Maxwell

by Peter M. Harman

Cambridge University Press, £18.95, \$29.95

The Sun in the Church: Cathedrals As Solar Observations

by J. L. Heilbron

Harvard University Press, \$18.95, £12.95

“... John Heilbron's book tells a gripping story with a splendid literary flair ... Heilbron tells it in a masterfully human way... with his usual brilliant irony." George V. Coyne Nature 402, 579-580 (1999)

You Can't Eat GNP: Economics as if Ecology Mattered

by Eric A. Davidson

Perseus Publishing, $\$ 16$

Color Vision: From Genes to Perception edited by Karl R. Gegenfurtner \&

Lindsay T. Sharpe

Cambridge University Press, £42.95, \$59.95 